\title{
The safety of computerised prescribing in hospitals
}

\author{
Melissa T Baysari \\ Associate professor in \\ Digital Health',2
}

\section{Magdalena Z Raban Research fellow ${ }^{2}$ \\ ${ }^{1}$ Faculty of Health Sciences, The University of Sydney \\ ${ }^{2}$ Centre for Health Systems and Safety Research, \\ Australian Institute \\ of Health Innovation, \\ Macquarie University, \\ Sydney}

\section{Keywords}

computer-assisted drug therapy, decision support systems, electronic prescribing, medication errors

Aust Prescr 2019;42:136-8 https://doi.org/10.18773/ austprescr.2019.037

\section{SUMMARY}

The implementation of computerised prescribing can result in large reductions in prescribing error rates. The flow-on effects to patient outcomes are not well studied.

The reduction in errors is dependent on prescribers becoming proficient in using the electronic prescribing system. All potential safety benefits are therefore not expected to be achieved immediately.

Electronic prescribing systems introduce new types of errors, most frequently errors in selection. Some of these errors can be prevented if the system is well designed.

Computerised decision support embedded in electronic prescribing systems has enormous potential to improve medication safety. However, current support systems have a limited capacity to provide context-relevant advice to prescribers.

\section{Introduction}

Although most general practices are now computerised, ${ }^{1,2}$ Australia lags behind the USA in the adoption of electronic prescribing systems in hospitals. ${ }^{3}$ The key benefits of electronic prescribing systems include improved legibility, improved availability (anywhere and anytime) and improved continuity of care, for example by having rapid access to a patient's medication list from a previous admission. A major benefit is reducing medication errors. However, electronic prescribing systems can introduce new errors.

\section{Preventing medication errors}

Medication errors are among the most frequently reported incidents in hospitals and a major patient safety priority. The World Health Organization has announced the third Global Patient Safety Challenge to be 'medication without harm'. ${ }^{4}$ The Australian Commission on Safety and Quality in Health Care endorses the use of electronic prescribing systems for medication management in hospitals, suggesting that these programs can 'improve the safety and quality of health care'. ${ }^{5}$ But do they?

There is now considerable evidence to show that medication errors in hospitals decline following the implementation of electronic prescribing systems. ${ }^{6}$ The evidence includes an Australian-controlled beforeand-after study of the introduction of two commercial electronic prescribing systems in two Sydney hospitals. ${ }^{7}$ These interventions resulted in a large (>50\%) reduction in prescribing error rates. Whether this sizeable reduction in medication error led to improved outcomes for patients is uncertain. Very few studies go beyond evaluating the effect of electronic prescribing systems on medication errors, although a large Australian trial is currently attempting to measure the impact of the systems on patient harm. ${ }^{8}$

\section{Delayed benefits}

There is no evidence to show whether or not the benefits of electronic prescribing systems on medication errors are immediate. Researchers typically avoid the treacherous 'shakedown' phase, ${ }^{9}$ and wait for the use of electronic prescribing systems to become routine before measuring the postimplementation prescribing error rates.

Users of electronic prescribing systems describe the period immediately following implementation as risky, as prescribers attempt to navigate the unfamiliar, often unintuitive landscape that is computerised prescribing. ${ }^{10}$ Even if familiar with prescribing in one system, using a different system requires new training and practice as systems differ considerably in display, features, functions and navigation. This is in contrast to using the standard National Inpatient Medication Chart."

It is likely that the introduction of electronic prescribing systems results in a transient increase in prescribing errors, as users familiarise themselves with the system. This is followed by a substantial decline in errors (as reported in a large number of trials), once proficiency in computerised prescribing is achieved. Heightened vigilance and close monitoring of system use is therefore essential in the early stages of implementation, especially for the detection of unanticipated problems with the design of the system 
and its use or implementation, for example system glitches and gaps in training for prescribers.

\section{New errors}

Accompanying reports on the effectiveness of electronic prescribing systems is a growing body of evidence showing that these systems can introduce new types of errors. ${ }^{12,13}$ In a study of electronic prescribing system errors in the USA, researchers identified 22 types of medication error risks that were facilitated by the electronic system. ${ }^{13}$ These included errors such as doctors ordering drugs for the wrong patient, or using the wrong log-in, because the previous user had failed to log out of the system at the computer terminal.

These problems are not unique to the USA and evidence of electronic prescribing system-related errors in Australia is increasing. For example, in a survey of 664 users of electronic prescribing systems (doctors, nurses and pharmacists) in Victoria, 58\% of respondents said that they thought the electronic system had introduced new types of error. ${ }^{14} \mathrm{An}$ audit of discharge medications at a tertiary Brisbane hospital found more errors in computer-generated prescriptions than paper-based prescriptions..$^{15}$ In the one large-scale Australian study to quantify the rate at which these system-related errors occur, approximately $42 \%$ of prescribing errors were related to the use of an electronic prescribing system - that is 78 system-related errors per 100 patient admissions. ${ }^{16}$ The most frequent type of error was selection error, where prescribers made the wrong selection from a drop-down menu. An interesting result was that, although the study was undertaken at two hospitals, each using a different electronic prescribing system, the overall rate of system-related errors was equivalent at both sites. However, selection errors were four times more likely in one hospital than the other. This reflected differences in the design of the systems (as one system required doctors to make many more selections from drop-down menus).

The design of electronic prescribing systems is important in preventing, or facilitating, prescribing errors. Placing the most frequently used items at the top of a drop-down menu is likely to minimise selection errors, as is limiting the number of options on a list. ${ }^{16,17}$ In a study that explored the use of lists of antibiotic orders in an electronic prescribing system, a doctor said 'Sometimes there are a lot of options...I know my colleagues have accidentally clicked the wrong dose just because there are a million different regimens or dosages'. ${ }^{18}$ As expected, the more choices a user is presented with, the longer they take to make a selection (the HickHyman Law ${ }^{19}$ ). This is an important rule to keep in mind when designing systems for use on a busy hospital ward. The result of presenting too many options in electronic prescribing systems is likely to be intentional mis-selection from a list, with users choosing the first option on a menu to save time.

\section{Decision support}

Despite the emergence of new types of errors, research has shown that computerised prescribing eliminates many more errors than it creates..$^{15}$ One of the fundamental components of electronic prescribing, perceived to be critical to achieving the anticipated benefits of improved safety and quality, is computerised decision support.

Common forms of computerised decision support include alerts and reminders, pre-written orders and order sets, calculators, and access to online reference material. ${ }^{20,21}$ However, decision support is also implicit in the design of electronic prescribing systems. For example, limiting the options on a drop-down menu to doses that are appropriate for a drug can prevent a dose 10 times larger than intended being prescribed. Preventing prescribers from ordering a drug unless a patient's allergies (or 'no allergy') are entered into the electronic prescribing system, can avoid a patient receiving a drug to which they are allergic.

\section{Problems}

Although the potential of computerised decision support is enormous, the enthusiasm for what is possible has overshadowed a careful consideration of the users and the environment in which they work. In many cases, the result has been a significant misalignment of computerised decision support and prescriber workflow. Alert fatigue, an inevitable consequence of too many alerts being presented, is an established and enduring problem for prescribers. ${ }^{22}$ Automation bias, a user's over-reliance on the system to detect errors ('the system did not alert me, so the prescription is OK'), is also a risk for prescribers. ${ }^{23}$

Not all computerised decision support integrates well with hospital clinical information systems, and current computerised decision support systems are unlikely to capture all types of errors. In taking a closer look at the types of prescribing errors that declined following the implementation of electronic prescribing in two Australian hospitals, the majority of the decline was in procedural errors such as incomplete and illegible orders. ${ }^{7}$ The computerised systems were not as effective in targeting clinical errors, such as the wrong doses and wrong drugs, which are the types of error that could be prevented by well-designed computerised decision support.

Different electronic prescribing systems (and different configurations of the same electronic prescribing 
systems) include varying levels and types of computerised decision support. ${ }^{7}$ This is the case even for the same types of decision support. For example, there is no standardised list of drug-drug interaction alerts to include in a system or a standardised way to present information in an alert, resulting in high variability across systems. ${ }^{24}$ This is despite users being fairly consistent in their preferences for how alert information should be displayed. ${ }^{25}$ Variability is particularly challenging for prescribers who work across multiple sites or organisations. Inconsistencies between electronic prescribing systems are something prescribers should keep in mind. User training should include clear information about the computerised decision support capabilities of the particular system the prescribers will be using.

\section{Solutions}

For computerised decision support to reach its full potential, smarter programs are needed. These would not assume that all patients are non-geriatric (or all are geriatric) and have normal physiological function. Computerised decision support should be context-aware to trigger alerts only when relevant for a particular patient (age, renal function) and when a particular drug form, dose, or frequency is prescribed. Although trials of smart computerised decision support have begun to emerge in the USA, ${ }^{26,27}$ Australia is not quite there yet.

\section{Conclusion}

There is now little doubt that computerised prescribing reduces medication errors in hospitals. However, it also introduces new types of errors. Well-designed systems that provide context-relevant information to prescribers are likely to result in the largest benefits to users and patients. $<$

Conflict of interest: none declared

\section{REFERENCES}

1. Henderson J, Pollack A, Gordon J, Miller G. Technology in practice - GP computer use by age. Aust Fam Physician 2014;43:831.

2. Henderson J, Britt H, Miller G. Extent and utilisation of computerisation in Australian general practice. Med J Aust 2006;185:84-7.

3. The Office of the National Coordinator for Health Information Technology. Quick Stats [Internet]. Washington: ONC; 2018. https://dashboard.healthit.gov/ quickstats/quickstats.php [cited $2019 \mathrm{Jul} 1]$.

4. Donaldson LJ, Kelley ET, Dhingra-Kumar N, Kieny MP, Sheikh A. Medication Without Harm: WHO's Third Global Patient Safety Challenge. Lancet 2017;389:1680-1. https://doi.org/10.1016/S0140-6736(17)31047-4

5. Australian Comission on Safety and Quality in Health Care. Electronic medication management [Internet]. Sydney: ACSQHC; 2019. https://www.safetyandquality.gov.au/our-work/medication-safety/ electronic-medication-management [cited $2019 \mathrm{Jul} 1]$

6. Radley DC, Wasserman MR, Olsho LE, Shoemaker SJ, Spranca MD, Bradshaw B. Reduction in medication errors in hospitals due to adoption of computerized provider order entry systems. J Am Med Inform Assoc 2013;20:470-6. https://doi.org/10.1136/amiajnl-2012-001241

7. Westbrook JI, Reckmann M, Li L, Runciman WB, Burke R, Lo C, et al. Effects of two commercial electronic prescribing systems on prescribing error rates in hospital in-patients: a before and after study. PLoS Med 2012;9:e1001164. https://doi.org/10.1371/journal.pmed.1001164

8. Westbrook JI, Li L, Raban MZ, Baysari MT, Mumford V, Prgomet M, et al. Stepped-wedge cluster randomised controlled trial to assess the effectiveness of an electronic medication management system to reduce medication errors, adverse drug events and average length of stay at two paediatric hospitals: a study protocol. BMJ Open 2016;6:e011811. https://doi.org/10.1136/ bmjopen-2016-011811

9. Sykes TA, Venkatesh V, Rai A. Explaining physicians' use of EMR systems and performance in the shakedown phase. J Am Med Inform Assoc 2011;18:125-30. https://doi.org/10.1136/jamia.2010.009316

10. Baysari MT, Hardie RA, Lake R, Richardson L, McCullagh C, Gardo A, et al. Longitudinal study of user experiences of a CPOE system in a pediatric hospital. Int J Med Inform 2018;109:5-14. https://doi.org/10.1016/j.ijmedinf.2017.10.018

11. Coombes ID, Reid C, McDougall D, Stowasser D, Duiguid M, Mitchell C. Pilot of a National Inpatient Medication Chart in Australia: improving prescribing safety and enabling prescribing training. Br J Clin Pharmacol 2011;72:338-49. https://doi.org/10.1111/j.1365-2125.2011.03967.x

12. Korb-Savoldelli V, Boussadi A, Durieux P, Sabatier B. Prevalence of computerized physician order entry systems-related medication prescription errors: a systematic review. Int J Med Inform 2018;111:112-22. https://doi.org/ 10.1016/j.ijmedinf.2017.12.022

13. Koppel R, Metlay JP, Cohen A, Abaluck B, Localio AR, Kimmel SE, et al. Role of computerized physician order entry systems in facilitating medication errors. JAMA 2005;293:1197-203. https://doi.org/10.1001/jama.293.10.1197

14. Van de Vreede M, Clifford J, McGrath A. Staff experience and perceptions of the safety and risks of electronic medication management systems in Victorian public hospitals. J Pharm Pract Res 2018;48:18-25. https://doi.org/ 10.1002/jppr.1327
15. Coombes ID, Stowasser DA, Mitchell CA, Varghese P. Effect of computerised prescribing on use of antibiotics. Med J Aust 2004;180:140-1.

16. Westbrook JI, Baysari MT, Li L, Burke R, Richardson KL, Day RO. The safety of electronic prescribing: manifestations, mechanisms, and rates of system-related errors associated with two commercial systems in hospitals. J Am Med Inform Assoc 2013;20:1159-67. https://doi.org/10.1136/ amiajnl-2013-001745

17. Ahmed Z, Garfield S, Jani Y, Jheeta S, Franklin BD. Impact of electronic prescribing on patient safety in hospitals: implications for the UK. Clin Pharm 2016;8. www.pharmaceutical-journal.com/research/review-article/impactof-electronic-prescribing-on-patient-safety-in-hospitals-implications-for-theuk/20201013.article [cited 2019 Jul 1]

18. Baysari MT, Del Gigante J, Moran M, Sandaradura I, Li L, Richardson KL, et al. Redesign of computerized decision support to improve antimicrobia prescribing. A controlled before-and-after study. Appl Clin Inform 2017;8:949-63. https://doi.org/10.4338/ACI2017040069

19. Seow S. Information theoretic models of $\mathrm{HCl}$ : a comparison of the Hick-Hyman Law and Fitts' Law. Hum Comput Interact 2005;20:315-52. https://doi.org/ 10.1207/s15327051hci2003_3

20. Wright A, Sittig DF, Ash JS, Feblowitz J, Meltzer S, McMullen C, et al. Development and evaluation of a comprehensive clinical decision support taxonomy: comparison of front-end tools in commercial and internally developed electronic health record systems. J Am Med Inform Assoc 2011;18:232-42. https://doi.org/10.1136/amiajnl-2011-000113

21. Kuperman GJ, Bobb A, Payne TH, Avery AJ, Gandhi TK, Burns G, et al. Medication-related clinical decision support in computerized provider order entry systems: a review. J Am Med Inform Assoc 2007;14:29-40. https://doi.org/10.1197/jamia.M2170

22. Payne TH. EHR-related alert fatigue: minimal progress to date, but much more can be done. BMJ Qual Saf 2019;28:1-2. https://doi.org/10.1136/ bmjas-2017-007737

23. Lyell D, Magrabi F, Raban MZ, Pont LG, Baysari MT, Day RO, et al. Automation bias in electronic prescribing. BMC Med Inform Decis Mak 2017;17:28. https://doi.org/10.1186/s12911-017-0425-5

24. Lowenstein D, Zheng WY, Burke R, Kenny E, Sandhu A, Makeham M, et al. Do user preferences align with human factors assessment scores of drug-drug interaction alerts? Health Informatics J 2019 Apr 11:1460458219840210 [Epub ahead of print] https://doi.org/10.1177/1460458219840210

25. Yu KH, Sweidan M, Williamson M, Fraser A. Drug interaction alerts in software--what do general practitioners and pharmacists want? Med J Aust 2011;195:676-80. https://doi.org/10.5694/mja11.10206

26. Duke JD, Li X, Dexter P. Adherence to drug-drug interaction alerts in highrisk patients: a trial of context-enhanced alerting. J Am Med Inform Assoc 2013;20:494-8. https://doi.org/10.1136/amiajnl-2012-001073

27. Riedmann $D$, Jung $M$, Hackl WO, Stühlinger $W$, van der Sijs $H$, Ammenwerth $E$. Development of a context model to prioritize drug safety alerts in CPOE systems. BMC Med Inform Decis Mak 2011;11:35. https://doi.org/10.1186/ $1472-6947-11-35$ 